\title{
Ox cart accidents as a cause of spinal cord injury in Tanzania
}

\author{
Haleluya I. Moshi $\mathbb{1}^{1,2} \cdot$ Mubashir A. Jusabani ${ }^{1,3} \cdot$ Sakina M. Rashid $\mathbb{1}^{4} \cdot$ Marieke C. J. Dekker $^{1,5,6}$
}

Received: 10 March 2020 / Revised: 24 October 2020 / Accepted: 30 October 2020

(c) The Author(s), under exclusive licence to International Spinal Cord Society 2020

\begin{abstract}
Study design Prospective Study.

Objectives To describe a unique site-specific injury mechanism for spinal cord injury: incidents involving ox-carts. Setting Main referral hospital for North-eastern Tanzania.

Methods A prospective cohort study on Spinal Cord Injury (SCI) in a tertiary referral center in North-eastern Tanzania was examined for accidents related to the use of ox-carts, a major means of transport in a rugged rural area where the economy is largely based on agricultural practices.

Results Five out of a total of 163 individuals admitted with SCI were injured in incidents directly related to the use of oxcarts. On admission each of the five individuals had different neurological level and corresponding injury severity as follows; C4 (American Spinal Injury Association Impairment Scale) AIS A), C5 (AIS D), C7 (AIS C), T1 (AIS C) and L1 (AIS D). Two out of the five patients developed secondary complications during their hospital stay.

Conclusion The nature of these injuries highlights the influence of one's environment and social circumstances on the risk of sustaining a SCI. Such cases also serve to illustrate the need for tailored prevention, rehabilitation, and reintegration into society.
\end{abstract}

\section{Introduction}

Spinal cord injuries (SCI) result in an acute and lasting change of life. Due to acquired disability, a member of a household may suddenly end up dependent in basic activities with unaffordable expenses. In a low-income country this is compounded by a suboptimal healthcare infrastructure, a lack of

Haleluya I. Moshi

luluwayesu@gmail.com

1 Orthopedic Rehabilitation Unit, Kilimanjaro Christian Medical Centre, Moshi, Tanzania

2 Kilimanjaro Christian Medical University College, Moshi, Tanzania

3 Department of Orthopedics and Trauma, Kilimanjaro Christian Medical Centre, Moshi, Tanzania

4 Division of Neurosurgery, Groote Schuur Hospital, Cape Town, South Africa

5 Department of Pediatrics and Child Health, Kilimanjaro Christian Medical Centre, Moshi, Tanzania

6 Department of Internal Medicine, Kilimanjaro Christian Medical Centre, Moshi, Tanzania skilled personnel and limited opportunities for adequate rehabilitation [1].

Variable geography, sociocultural factors, and economic activities account for differences in the leading causes of trauma and SCIs [2]. These differences in leading causes are also evident in the global map of SCI [3]. Generally, there is a number of socioeconomic activities carried out with minimal occupational health measures, hence increased risk of trauma and SCI, in rural low-income countries [4, 5]. These include informal and less regulated socioeconomic activities such as traditional sports, repeatedly climbing trees for various reasons, heavy head loading activities, and close human-vehicle proximity due to insufficient road space [4]. Human-animal interaction is common especially among rural and farming communities [6]. Animal-related accidents and injuries are common in many parts of the world [7-9]. Amongst less common causes of SCI are those involving interaction of people and animals during sports and transportation such as horse riding and bull riding or fighting [10]. The recorded traumatic incidents from horse riding take us as far back as 1392 although it can be earlier than this period [11]. In the early 90's studies in Poland and Romania, reported horse-cart accidents were among the leading causes of SCI $[12,13]$. Livestock and machineryrelated TSCIs may have been reported in rural farming 
communities in Ireland and India [14]. In Asia for instance, ladies' long scarves become caught in rickshaw wheels and other machineries causing cervical SCIs [12].

Worldwide, two leading causes of TSCIs are road traffic accidents and falls [15]. Literature from North East Tanzania lists fall (especially from trees) and Road Traffic Crashes as the leading causes of TSCI [16-18]. However, in the ongoing prospective study a substantial number (between 4 and 11\%) of cases results from more uncommon causes. More of these peculiar causes were mentioned in other studies from the same setting [18]. Amongst these statistics is a sub-group of patients with a rather peculiar mode on injury: ox cart accidents.

Primary prevention in Sub-Saharan Africa (SSA) is vital and depends on knowledge of site-specific risk factors. Northern Tanzania is a primarily rural society with smallscale agricultural activities generating the primary household income for the majority of the population [3, 4]. Our referral hospital receives patients from more urbanized as well as very rural regions. We recently described a bird hunter from Central Tanzania who presented with TSCI due to being accidentally shot in the neck with an arrow [19], clearly an uncommon cause of SCI. Local trauma mechanism patterns help identify risky practices, which should be considered in prevention programs. We identified a group of patients who all originated from the same poorly accessible, rugged pastoralist small-scale farming region, presenting with a unique trauma mechanism. This same environment later means an extra rehabilitation obstacle in terms of mobility. This study describes TSCI due to falls from ox carts and ox-related injuries from a specific region around the Ngorongoro Crater.

\section{Methods}

This prospective hospital-based review of TSCI resulting from ox cart injuries was conducted in the Department of Orthopedics and Trauma of the Kilimanjaro Christian Medical Centre (KCMC). This center is an academic referral medical facility in the Kilimanjaro Region of Tanzania with bed capacity of more than 660. KCMC serves the entire North-east of the country and also receives patients from across the border from the neighboring country of Kenya. It is home to the only SCI rehabilitation center in the country. Medical ethical clearance for this study was obtained within the frame of a broader study on TSCI in KCMC (certificate number 620).

The study period was from January 2018 to December 2019. All patients who sustained TSCI after accidents with ox carts and were included. Patients who presented with all TSCI, including those sustained due to oxcart injuries, were entered into the database. Information detailing socio- demographic characteristics, neurological and skeletal level of injury, concomitant injuries, secondary complications and mortality before discharge were recorded as per the SCI Common Data Elements questionnaire. The International Standards for Neurological Classification of Spinal Cord Injury was used for assessment of outcome on admission and discharge. This was a retrospective review of prospectively collected data. Data were entered into Statistical Package for the Social Sciences Version 23 software. Descriptive analysis was used for all variables due to the limited sample size.

We certify that all applicable institutional and governmental regulations concerning the ethical use of human records were followed during the course of this research. The photograph (Fig. 1) was taken with explicit permission by the person depicted.

\section{Results}

A total of 163 TSCI patients were admitted to our centre during the study period. Ten (6.1\%) were from the Manyara region of whom six had sustained SCI in incidents involving ox carts. The Manyara region is an $\sim 100$ by 100 kilometer region in Central Tanzania. Four individuals were run over by ox carts and sustained incomplete cervical level injuries and one fell off ox carts and suffered injury at the thoracolumbar level (Table 1). Individuals with a cervical spinal injury were placed on halo traction for 6 weeks. In the event that complications developed before the completion of 6 weeks, the patient completed the remaining period in a rigid neck collar. None of them had health insurance coverage.

\section{Discussion}

This mechanism for TSCI readily illustrates the socioeconomic conditions in the Manyara region, where farmland transport is largely done by ox carts. Ox carts are usually ridden by men but with changing breadwinner roles, raising population density and drought, women are also increasingly involved in such activities. Generally, these are injuries of a lesser incidence [9] and clinical and functional outcomes are relatively better than that seen in road traffic and falls from height. This observation can be explained by the fact that ox cart transport is relatively low weight and velocity [20].

The weight of an ox is about 400 kilograms (kgs), with an estimated maximum cart speed of $5-10 \mathrm{~km} / \mathrm{h}$ (personal communication with villagers). This implies that weight of a loaded cart minus that of the driver (estimated $70 \mathrm{kgs}$ ) will be about $330 \mathrm{kgs}$. This weight is more or less similar to the commonly used bullock carts in India ranging from 310 to 


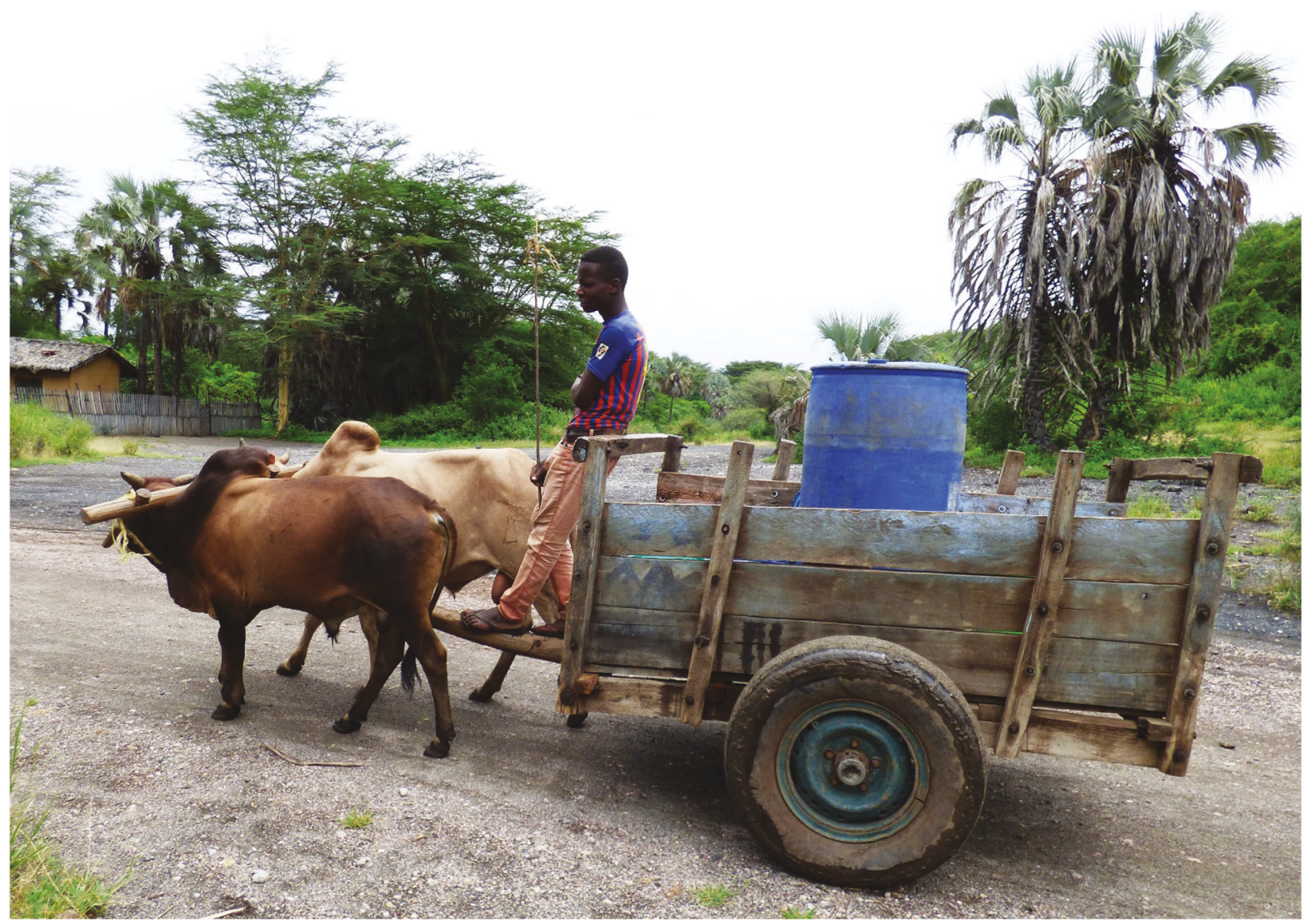

Fig. 1 An ox-cart with a water-filled container and the rider. The ox cart is mainly made of wood, with less safety considerations and their riders hardly take any precautions.

Table 1 SCIWORA: spinal cord injury without obvious radiological abnormality.

\begin{tabular}{llllllll}
\hline $\begin{array}{l}\text { Patient } \\
\text { number }\end{array}$ & Sex & $\begin{array}{l}\text { Age } \\
\text { (Years) }\end{array}$ & $\begin{array}{l}\text { Skeletal injury } \\
\text { (radiological findings) }\end{array}$ & $\begin{array}{l}\text { Neurological } \\
\text { Level of injury }\end{array}$ & $\begin{array}{l}\text { AIS score } \\
\text { (Admission) }\end{array}$ & $\begin{array}{l}\text { AIS score } \\
\text { (Discharge) }\end{array}$ & Complications \\
\hline 1 & Male & 40 & C5 and C6 & C5 & D & D & None reported \\
2 & Female & 30 & C6 and C7 & C7 & C & D & Pressure injury \\
3 & Male & 25 & C4 and C5 & C4 & A & Pressure ulcer, paralytic ileus, \\
urinary tract infection
\end{tabular}

*SCIWORA* Spinal cord injury without obvious radiological abnormality.

$350 \mathrm{~kg}$ [20]. The indigenous in our study estimate their loaded ox carts speed are faster than Indian bullock carts $(3 \mathrm{~km} / \mathrm{h})$. It would be unfair to compare the two speeds as in the Indian study [19], the bullock carts were loaded with $1100 \mathrm{~kg}$ while the Tanzanian ox-carts transported mainly the rider. In any case, although the impact will be a fraction of that of any motor vehicle at a maximum speed, it is sufficient to inflict serious injury.

The clinical outcome of SCIs related to ox carts does seem to be better than other etiologies, albeit a conclusion based on small numbers. Nevertheless, the individuals with SCI will have to return and achieve mobility on a rugged terrain. Moreover, in this era of extreme drought and climate change which impacts Tanzania with extreme rainfall and increased erosion, risks of such injuries overall may be on the rise.

Under economically-constrained living conditions an individual with permanent disability struggles to satisfy self and family requirements as well as the added cost of rehabilitation. The cost includes access to limited 


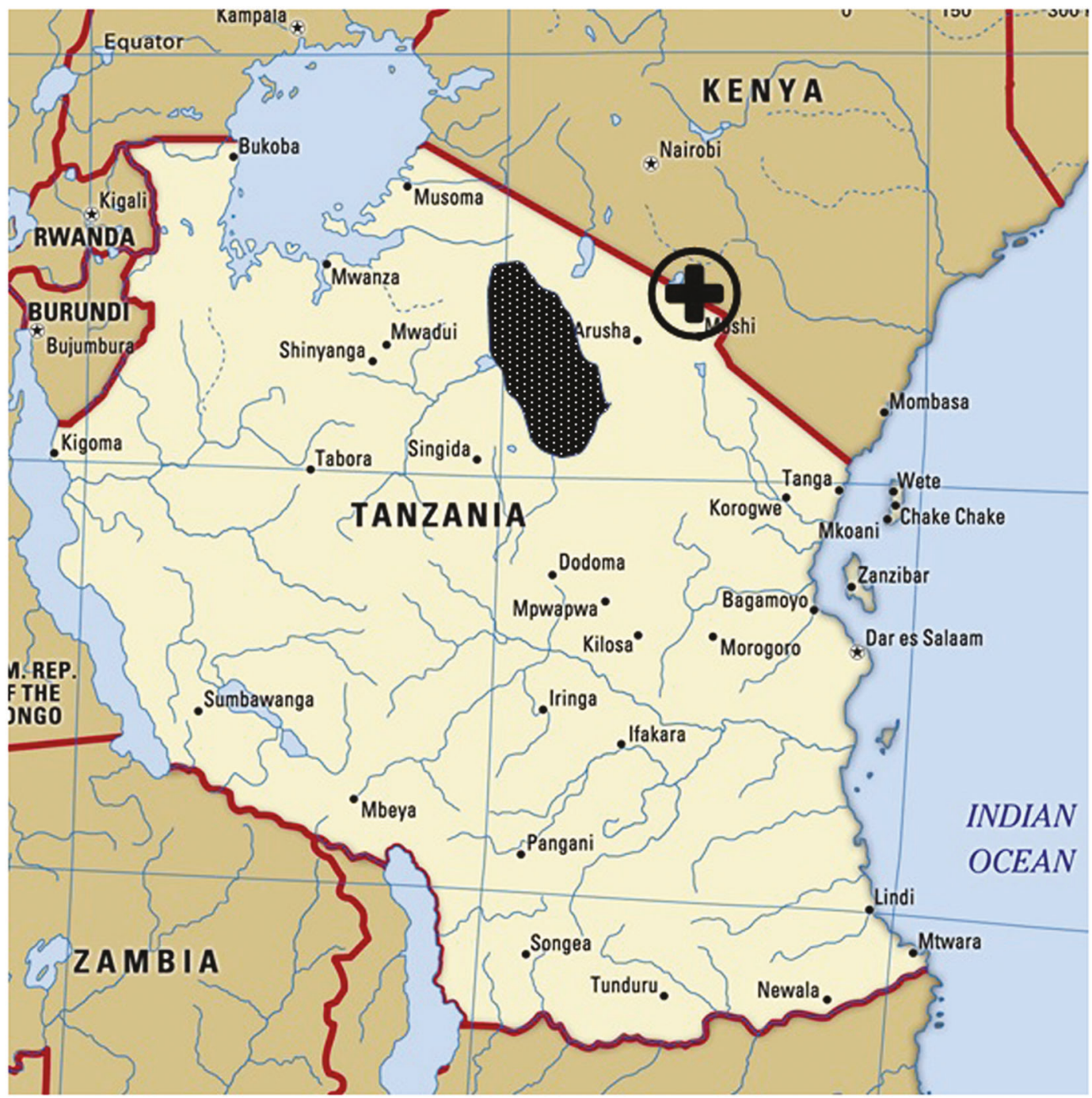

Fig. 2 Location of the Manyara region. 调 + Location of KCMC.

rehabilitation facilities, personnel and assistive devices within inaccessible environment. Tanzania has one of the lowest national healthcare coverage whereby only about $10 \%$ of the population have health insurance coverage [21]. This implies that the majority of the individuals who sustain long-term disability are dependent on their respective families in catering for healthcare and rehabilitation needs. Inability of the individuals or their families to cater for their health and rehabilitation services may explain why the majority are lost to follow up. Alternative means such as telerehabilitation and international initiatives such as "sustain our abilities" can potentially help individuals in these remote areas to have more control over their environment and health [22]. However, challenges such as availability of electricity and illiteracy are potential hindrances to the use of electronic devices. With current innovations and increase in the use of alternative sources of energy such as solar and biogas in rural Africa, electronic-based solutions are still a promising strategy in the near future.

This study has limitations, mainly due its sample size and its local character. Both make generalization of such observations difficult. There are also potentially confounding factors. To cover the distance from this rugged area to the tertiary referral center $\mathrm{KCMC}(255 \mathrm{~km})$ is a major financial and logistic obstacle. The number of individuals presenting to $\mathrm{KCMC}$ is likely smaller than the actual number incurring ox cart related SCI. On-site mortality of people with SCI is high $[4,23]$, leading to a possible underrepresentation of the actual group size, but this high mortality likely does not vary much across the country.

To have a completely representative impression this study would have had to be performed locally in the region under investigation (Fig. 2). Other issues come up during rehabilitation related to the distance to the site. Once 
patients are transferred to the rehabilitation unit at KCMC, family involvement with patient feeding, two-hourly turning and nursing care is initiated early to facilitate a more rapid transition to home life. Due to the distance between the patient's home and KCMC, family visits may be more infrequent. For patients whose families are a long distance away, the risk of malnutrition, bedsores and depression is likely higher which may negatively impact outcomes of individuals who come from far away.

Although our study cohort is small, information about SCIs from SSA is scarce and remains potentially informative to direct changes in care and research. Observations like these also serve as an illustration of the local and global variation in the mechanism of SCIs and the challenges faced by the injured and their dependents.

Acknowledgements Authors acknowledge voluntary effort of Sadi Mohammed and Chris Schmeling who took photographs of the ox cart and the rider from the referring region with explicit permission by the person depicted.

\section{Compliance with ethical standards}

Conflict of interest The authors declare that they have no conflict of interest.

Publisher's note Springer Nature remains neutral with regard to jurisdictional claims in published maps and institutional affiliations.

\section{References}

1. Øderud T. Surviving spinal cord injury in low income countries. Afr J Disabil. 2014;3:80.

2. Kumar R, Lim J, Mekary RA, Rattani A, Dewan MC, Sharif SY, et al. Traumatic spinal injury: global epidemiology and worldwide volume. World Neurosurg. 2018;113:e345-63.

3. Lee BB, Cripps RA, Fitzharris M, Wing PC. The global map for traumatic spinal cord injury epidemiology: update 2011, global incidence rate. Spinal Cord. 2014;52:110-6.

4. Moshi HI. Physical trauma and its consequences in rural and semiurban regions of low and middle income countries. In: Current Issues in Global Health 2018. IntechOpen; Missouri State University, USA, pp 225-34.

5. Wisborg T, Montshiwa TR, Mock C. Trauma research in low- and middle-income countries is urgently needed to strengthen the chain of survival. Scand J Trauma Resusc Emerg Med. 2011;19:62.

6. Tumram NK, Ambade VN, Dixit PG. Human fatalities caused by animal attacks: a six-year autopsy study. Med Leg J. 2017;85:194-9.
7. Gilyoma J, Mabula J, Chalya P. Animal-related injuries in a resource-limited setting: experiences from a Tertiary health institution in northwestern Tanzania. World J Emerg Surg. 2013;8:7.

8. Steele MT, Ma OJ, Nakase J, Moran GJ, Mower WR, Ong S, et al. Epidemiology of animal exposures presenting to emergency departments. Acad Emerg Med. 2007;14:398-403.

9. Patil SS, Kakade R, Durgawale P, Kakade S. Pattern of road traffic injuries: a study from Western maharashtra. Indian J Community Med. 2008;33:56-7.

10. Silver JR. Spinal injuries resulting from horse riding accidents. Spinal Cord. 2002;40:264-71.

11. Ki HC, Shin E-K, Woo EJ, Lee E, Hong JH, Shin DH. Horseriding accidents and injuries in historical records of Joseon Dynasty. Korea Int J Paleopathol. 2018;20:20-5.

12. Beigh Z, Ali I. Long Scarf Syndrome; Accidental Strangulation due to Long Scarf. J Health Edu Res Dev. 2016;4:1.

13. Soopramanien A. Epidemiology of spinal injuries in Romania. Paraplegia. 1994;32:715-22.

14. Berney MJ, Horstmann E, Cassidy N. Traumatic spinal injuries on farms: patients treated in the national spinal unit of Ireland 200515. J Orthop. 2017;14:211-5.

15. Georgiadou D, Zografos GN, Vaidakis D, Avlonitis S, Katopodi A, Tzirakis EN, et al. Swordfish bill injury involving abdomen and vertebral column: case report and review. BMC Surg. 2010;10:30.

16. Moshi H, Sundelin G, Sahlen K-G, Sörlin A. Traumatic spinal cord injury in the north-east Tanzania - describing incidence, etiology and clinical outcomes retrospectively. Glob Health Action. 2017;10:1355604.

17. Rashid SM, Jusabani MA, Mandari FN, Dekker MCJ. The characteristics of traumatic spinal cord injuries at a referral hospital in Northern Tanzania. Spinal Cord Ser Cases. 2017;3:17021.

18. Bellet FD, Rashid SM, Jusabani MA, Dekker MCJ, Temu RJ. The characteristics of cervical spinal cord trauma at a North Tanzanian Referral Hospital: a retrospective hospital based study. Pan Afr Med J. 2019;33:82.

19. van Adrichem DC, MRHA Ratering, Rashid SM, Jusabani MA, Poppe VE, Mwaitele HA, et al. Penetrating spinal cord injury causing paraplegia in a bird hunter in rural Tanzania. Spinal Cord Ser Cases. 2019;5:49.

20. Patre NK, Quasim M, Kumarand M, Tripathi A. Status of Bullock Carts and Comparative Evaluation of Different types of Cart available in Chhattisgarh Plains. Int $\mathbf{J}$ Pure Appl Biosci. 2018;6:1539-46.

21. Amu H, Dickson KS, Kumi-Kyereme A, Darteh EKM. Understanding variations in health insurance coverage in Ghana, Kenya, Nigeria, and Tanzania: Evidence from demographic and health surveys. PloS ONE. 2018;13:e0201833.

22. Letta M, Montalbano P, Tol RSJ. Temperature shocks, short-term growth and poverty thresholds: evidence from rural Tanzania. World Dev. 2018;112:13-32.

23. Sriram PR, Tsin Jien TC, Sellamuthu P. Backstabbing swordfish: a rare cause of traumatic hemiparesis. J Neurosurg Spine. 2017;27:158-60. 